\title{
BURN FROM DC DEFIBRILLATOR, A SMALL PRICE TO PAY: A CASE REPORT
}

\author{
Naba Kumar Pattnaik1, Prasanna Kumar Mishra²
}

${ }^{1}$ Retired Professor, Department of CTVS, Consultant Apollo Hospital, Bhubaneswar.

${ }^{2}$ Retired Professor, Department of Anaesthesia, Consultant Apollo Hospital, Bhubaneswar.

\section{ABSTRACT}

Ventricular Fibrillation (VF) is a Medical Emergency and Defibrillation is the definite treatment with DC shock. The correct application of energy by trained personnel is important for success and to avoid complications. We describe herewith an interesting case of several episodes of VF requiring emergency treatment. The patient survived the ordeal with several burns on the chest wall.

\section{KEYWORDS}

VF, Defibrillation, Defibrillator Burn.

HOW TO CITE THIS ARTICLE: Pattnaik NK, Mishra PK. Burn from DC defibrillator, a small price to pay: a case report. J. Evolution Med. Dent. Sci. 2016;5(83):6226-6227, DOI: 10.14260/jemds/2016/1406

\section{INTRODUCTION}

A young patient (ND) of 28 years male had some dysrhythmia from childhood and was on a pacemaker for last seven years. The history revealed the patient coming from rural areas, in his early adulthood, was having syncopal attack off and on. The general practitioner who examined him found him to have some irregularity in his pulse and referred him to the cardiologist for evaluation. The youngman was otherwise fit. His ECG had shown some abnormality, which he could not specify. A $24 \mathrm{hrs}$. Holter study at that time showed that he has more problem and was advised to put a pacemaker. After sometime he was given a pacemaker, which was implanted in right upper chest for last seven years. He was hale and hearty and there was no syncopal attack anymore for several years.

For last three months, he was again having chest discomfort and blackout episodes and again seen by a different Cardiologist. This time it was found that the pacemaker is fully functional, but the patient is developing occasional chest discomfort due to ventricular fibrillation. As the incidence of attack increased in frequency, he was re-evaluated and it was also found that he has some degree of Cardiomyopathy too. So he was admitted to ICU.

On admission he was afebrile, Pulse was $82 / \mathrm{min}$ with occasional extra beats. BP 116/80 mmHg. On clinical examination, he was anxious. His heart sounds were normally heard. There was no murmur. Breath sounds heard in all quadrant. Other systems were normal. CBC was within normal limits (Hb 11.4 gm\%, TLC 8900). Blood Sugar 102 mg\%, serum Urea $44 \mathrm{mg}$, Creatinine 0.8, Na 132 and $\mathrm{K}$ was $3.8 \mathrm{mEq} / \mathrm{L}$. Liver function tests were within normal limits and x-ray chest showed the pacemaker in situ with pacemaker electrode in place,

Financial or Other, Competing Interest: None.

Submission 25-09-2016, Peer Review 08-10-2016,

Acceptance 11-10-2016, Published 17-10-2016.

Corresponding Author:

Dr. Naba Kumar Pattnaik,

Plot No. $1211 / C$,

Sector-6,

CDA, Bidanasi,

Cuttack-753014, Odisha.

E-mail:drnkpattnaik.ctvs@gmail.com

DOI: $10.14260 /$ jemds $/ 2016 / 1406$ cardiac shadow was slightly larger than normal size with clear lung fields. ECG shows HR 82/min with pacemaker spikes; 2D echo showed normal 4 chamber with normally functioning valves, mild left ventricular enlargement, good LV function with EF of $55 \%$.

Within hours of admission, he first developed chest discomfort and became unconscious. The alarm in monitor indicated a VF with asystole. The patient was given external cardiac massage and defibrillation done with 260 joules and the rhythm was converted to regular rhythm. The patient recovered. A Trop-T test showed no myocardial damage.

He was advised complete rest in bed. An IV started for KVO. He was given Tab. Amiodarone $200 \mathrm{mg}$ twice daily, Tab. Pantoprazole and Injection of $1 \mathrm{gm}$ Ceftriaxone twice daily. While in hospital bed, the frequency of VF increased. A BPL defibrillator was kept at his bedside for quick and early defibrillation.

The patient was very anxious. He was waiting for a new pacemaker with defibrillator AICD (Automated Internal Cardiac Defibrillator) to be arranged. The relatives were counselled for early action of implant of new device and the risk of the procedure.

In the ICU, he suffered repeated attacks of VF and arrested several times. A DC defibrillator (BPL make) was kept by his bedside to be used as and when required. He was resuscitated by the ICU staff who also applied DC shock with 200 - 300 joules with the defibrillator. He had total 18 episodes of VF for which he was defibrillated.

The sisters in ICU gets panic while the patient goes to VF. In the process of application of jelly, correct placement of PADS were not meticulously followed in some occasions. Panic and inexperience led to wrongful application of defibrillator pads. In the process he had several burn injury to the chest wall. (Photograph-1) The patient was finally implanted a pacemaker with defibrillator (AICD). He was kept on observation and antiarrhythmic drugs were prescribed along with antibiotics and was treated for burn injury with topical application of Antiseptic ointment and oral analgesics. He survived the ordeal and was discharged without any further complication after 7 days. 


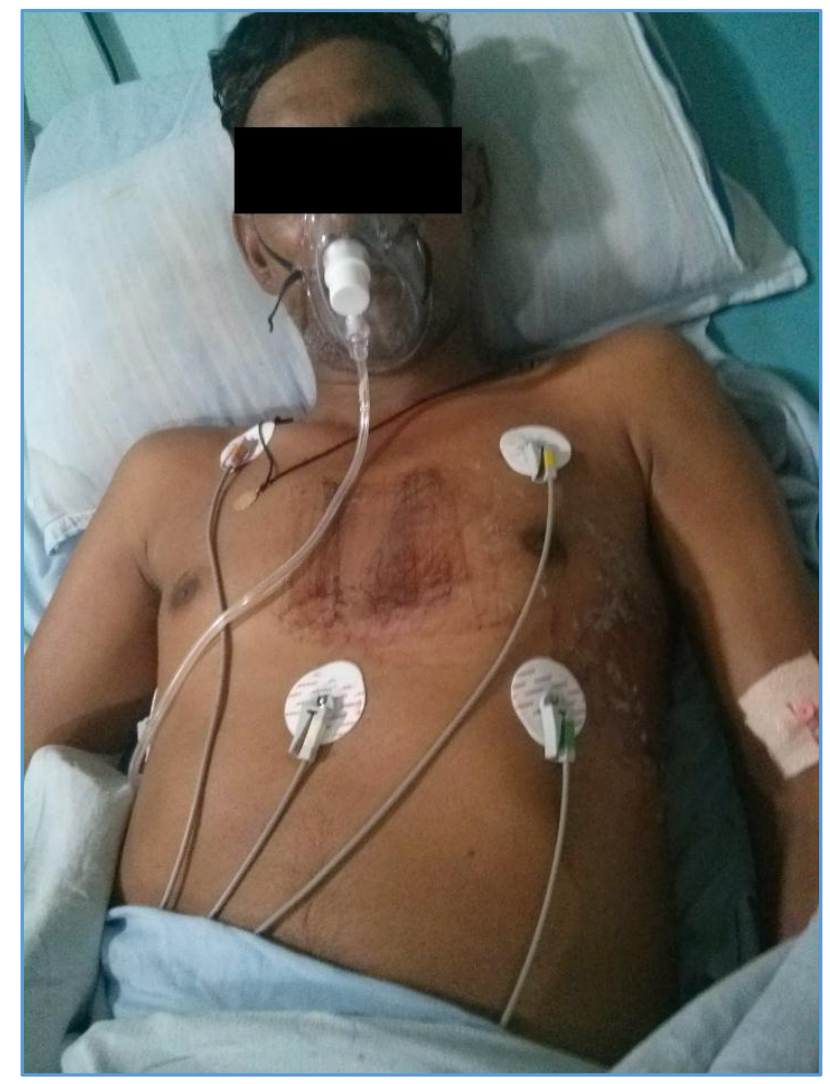

Defibrillator Burn

\section{DISCUSSION}

The old generation pacemakers were not intelligent enough to detect a VF if any. Later on the patient had on several occasions chest discomfort and loss of consciousness for short duration and this was thought to be due to infrequent VF which he luckily survived.

Defibrillation is a common treatment for life-threatening cardiac dysrrythmias and Ventricular Fibrillation (VF).

In 1899 Jean Louis Prevost and Frederik Battelie two physiologists from the University of Geneva, Switzerland, demonstrated small electrical shock could induce VF in dogs and that large current reverses the condition. In 1947, the equipment to deliver a shock was first used in a 14-year-old boy successfully by Claude Beck (Professor of Surgery). Until 1950, defibrillation was done only when chest cavity was open. Then external pads were developed and used for external defibrillation. Defibrillation can be external, transvenous or implanted. A DC current of 100-300 joules of energy is delivered for successful defibrillation.

Now-a-days, Biphasic wave form DC shock is advocated and is more effective. Indication of defibrillation include:

1. Pulseless VT (Ventricular Tachycardia).

2. VF.

3. Cardiac arrest due to or resulting from VF.
AHA (American Heart Association) guidelines 2010 for defibrillation or pulseless VT is as follows: Monophasic DC Shock - 360 joules, Biphasic shock - 120-200 joules.(1)

The Author has used 50 joules of energy and successfully reverted VF to sinus rhythm.(2)

The most common complications of Defibrillation is harmless arrhythmia. Serious complication may occur as VF, thromboembolisation or myocardial necrosis. Moderate-tosevere burn can occur in $20-25 \%$ of patients, $(3,4)$ most likely due to improper technique and electrode placement.(5) Interface with patient through the chest pads are provided with electrically conducted gel and reduce electrical resistance. If resistance increases, heat is generated and electrical burn occurs. A good contact with a force of $25 \mathrm{lbs}$ of force is needed if a series of shock is to be delivered. Use of biphasic current and gel based pads can reduce the incidence and severity of burn.(6,7)

Despite great deal of care and concern by medical personnel in ICU, patient continues to suffer inadvertent skin injury. Such injury may prolong morbidity and extended hospitalisation. Proper training of ICU personnel and to follow the protocol and guidelines is very much essential to reduce the incidence of skin burn. ${ }^{(8)}$

\section{REFERENCES}

1. Link MS, Atkin DL, Passman RS, et al. Electrical therapies AED, defibrillation, cardioversion and pacing: 2010 AHA guidelines for CR and emergency cardiovascular care. Circulation 2010;122(18 Suppl 3):S706-19.

2. Mishra PK. Successful defibrillation with 50 joules. http://criticalanasthesiabypkmishra.blogspot.com. 2014

3. DeSilva RA, Graboys TB, Podrid PJ, et al. Cardioversion and defibrillation. Am Heart J 1980;100(6 Pt 1):881-95.

4. Woodcock E. Cardiac arrhythmia-anatomic \& pathophysiologic concept. In: Guiliani ER, Gersh BJ, McGooh MD, et al. eds. Myo clinic-practice of cardiology. $3^{\text {rd }}$ edn. St Louis, MO: Mosby 1996:727-47.

5. Kirkland S, Stiell L, Alshawabkeh T, et al. The efficacy of pad placement for electrical cardioversion of atrial fibrillation/flutter: a systematic review. Acad Emerg Med 2014;21(7):717-26.

6. Kirchhof P, Monning G, Wshmer K. A trial of self-adhesive patch electrodes and hand-held paddle electrode for external cardioversion of atrial fibrillation (MOBIPAPA): Eur Heart J 2005;26(13):1292-7.

7. Berg RA, Sanders AB, Kern KB, et al. Adverse hemodynamic effects of interrupting chest compressions for rescue breathing during cardiopulmonary resuscitation for ventricular fibrillation cardiac arrest. Circulation 2001;104(20):2465-70.

8. Bailey SL. Electrical injuries. Considerations for the perioperative nurse. AORN J 1989;49(3):773-87. 